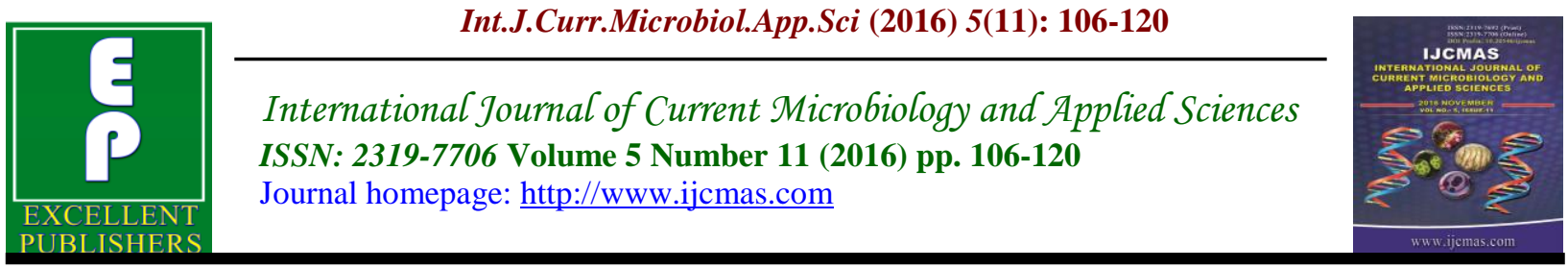

Original Research Article

http://dx.doi.org/10.20546/ijcmas.2016.511.012

\title{
Comparative Study of Different Methods of Detection of $\beta$-lactamase Production in Gram Negative Bacterial Isolates and Studying Induction of Resistance to Cefipime
}

\author{
Moustafa A. El-Nakeeb, Hoda M. Omar, Rania Abozahra* and Eman Badr \\ Pharmaceutical Microbiology Department, Faculty of Pharmacy, Damanhour University, \\ Damanhour, Egypt \\ *Corresponding author
}

Keywords

Gram-negative; $\beta$-lactamase detection; cefepime; induction of resistance

\section{Article Info}

Accepted: 04 October 2016 Available Online: 10 November 2016

\section{A B S T R A C T}

Extended spectrum $\beta$-lactamase (ESBLs) are enzymes produced by Gram negative bacteria. They are able to hydrolyze extended spectrum cephalosporins, penicillins and monobactams but inactive against cephamycin and imipenem. Various phenotypic methods are used in the routine practice to detect the ESBL production in Gram-negative bacilli. However detection of AmpC $\beta$-lactamases is not very common. This study aimed to detect the resistance pattern of cefepime, a fourth generation cephalosporin, among the tested Gram negative isolates collected from Egypt and to compare different phenotypic methods for the detection of ESBL and AmpC production in these isolates. We also studied the induction of cefepime resistance among the tested isolates and tested the stability of this induced resistance. A total of 113 Gram negative clinical isolates were studied. Three dimensional test detected ESBLs in $54(55.1 \%)$ isolates, whereas the double disc synergy test detected ESBLs in $47(48 \%)$ isolates these results were confirmed by the CLSI confirmatory test. The three dimensional test has been found to be better than Double disc synergy test in the detection of ESBLs. Most of the ESBL producing organisms are multidrug resistant. Cefepime was found to be able to induce resistance towards itself in all the selected isolates, this resistance was found to be stable in the tested isolates. Therefore cefepime should not be used alone for prolonged periods because it induces self-resistance by stimulating bacteria to produce $\beta$-lactamases.

\section{Introduction}

The relationship between the use of a specific antibiotic and the emergence of resistant strains in hospital flora is often difficult to establish. However, outbreaks of 
particular types of resistance have occurred after increased use of a particular antibiotic, especially when the drug is used as empirical monotherapy. Such outbreaks tend to cease when the antibiotic is used less or its use is discontinued (Naumovski et al., 1992).

$\beta$-lactamases are the greatest source of resistance to $\beta$-Lactams which are the most widely used antibiotics. It appears probable that all bacteria produce $\beta$-lactamases that are usually chromosomal, these $\beta$ lactamases are specific to the sub-species level. (Sykes and Matthew, 1976). Since the introduction of cephalosporins in the 1960s, plasmid-mediated $\beta$-lactamases have been produced by Enterobacteriaceae, Pseudomonas spp and other Gram-negative organisms. However, overuse of extended spectrum cephalosporins resulted then in the emergence of extended-spectrum $\beta$ lactamases (ESBLs) through point mutations in the existing broad-spectrum $\beta$-lactamases, such as TEM and SHV enzymes (O Gutkind et al., 2013). These enzymes are capable of inactivating extended-spectrum cephalosporins (ex: cefepime) and monobactams, as well as the earlier generation cephalosporins and penicillins. ESBLs have been identified in many different genera of Enterobacteriaceae and in Pseudomonas aeruginosa. However, they are most common in Klebsiella pneumoniae and Escherichia coli. They are plasmid mediated and are inhibited by $\beta$-lactamase inhibitors, such as clavulanic acid (Heffernan et al., 2007). Gram-negative bacteria with ESBL mediated resistance to cephalosporins have been progressively increasing in many parts of the world due to the acquisition of plasmids containing genes that encode for ESBLs (Paterson, 2006).

Overuse of extended-spectrum $\beta$-lactams also gave rise to chromosomal mutations in regulatory genes which resulted in the overproduction of chromosomal AmpC genes (O Gutkind et al., 2013). AmpC $\beta$ lactamases hydrolyze third-generation cephalosporins and cephamycins (eg, cefoxitin), as well as the earlier generation cephalosporins and penicillins, they are poorly inhibited by $\beta$-lactamase inhibitors such as clavulanic acid and sulbactam (Yagi et al., 2005).

Many clinical diagnostic laboratories depend on traditional susceptibility tests to screen for ESBL production among Gram-negative bacterial isolates which unfortunately lacks both sensitivity and specificity to detect ESBLs (Bradford, 2001). Double disk synergy test (DDST) is another method of ESBL detection. The major advantage of this method is that it is technically simple. However this method has some disadvantages as reduced sensitivity when ESBL activity is very low, the inability of clavulanate to inhibit all ESBLs, the loss of clavulanate disc potency during storage and the inability of the test to detect ESBLs in strains that also produces chromosomal cephalosporinases (Thomson and Sanders, 1992). All these things cause diagnosis failure and misuse of antibiotics. Three dimentional test (3D) is another method to detect ESBL production in Gram-negative bacteria, it gives phenotypic evidence of ESBL-induced inactivation of extended spectrum cephalosporin without relying on the demonstration of inactivation of the $\beta$ lactamases by a $\beta$-lactamase inhibitor (Thomson and Sanders, 1992).

Cefepime, a fourth generation cephalosporine, may be a therapeutic option for invasive infections caused by AmpC $\beta$ lactamase-producing organisms. It has the advantage of penetrating bacterial outer membranes more rapidly than third generation cephalosporins, readily reaching its target and avoids $\beta$-lactamase inactivation. Additionally, it has a reduced 
affinity for $\beta$-lactamases (Tamma et al., 2013).

The aim of this study was to detect $\beta$ lactamase production among different Gram negative bacterial isolates obtained from Egypt and to compare different phenotypic methods used for the detection of extended spectrum $\beta$-lactamases (ESBLs) and AmpC enzymes. Also we aimed to determine the ability of cefepime to produce induced resistance in the tested isolates and to study the stability of this induced resistance.

\section{Materials and Methods}

\section{Bacterial strains}

A total of 113 Gram negative clinical isolates were obtained from different clinical samples, $57(50 \%)$ of which were from urine, $28(25 \%)$ from pus, $25(22 \%)$ from sputum and $3(3 \%)$ from blood. They were collected from Alexandria and Beheira governorates in Egypt over the period from March 2013 to December 2013. The identities of the tested isolates were based on the colony morphology and confirmed by the classical techniques; microscopical examination, growth on selective and differential media and by selective biochemical tests. Escherichia coli ATCC 8739 was used as a reference strain.

\section{Antimicrobial Susceptibility Testing}

The isolates were tested for their antimicrobial susceptibilities by the standard disc agar diffusion technique (Andrews and Testing, 2006). The following antibiotics were used; Amoxicillin (AML10 $\mu \mathrm{g}$ ), Amoxicillin/Clavulanic (AMC30 $\mu \mathrm{g}$ ), Azithromycin (AZM15 $\mu \mathrm{g}), \quad$ Cefepime (FEP30 $\mu \mathrm{g}), \quad$ Cefoperazone (CFP75 $\mu \mathrm{g})$, Ceftazidime (CAZ30 $\mu \mathrm{g})$, Ceftriaxone (CRO30 $\mu \mathrm{g})$ Cefuroxime (CXM30 $\mu \mathrm{g})$, Cephalexine (CL30 $\mu$ g), Chloramphenicol
(C30 $\mu \mathrm{g}), \quad$ Levofloxacin $\quad$ (LEV5 $\mu \mathrm{g}$ ), Meropenem (MEM10 $\mu \mathrm{g})$ Rifampin $(\mathrm{RD} 5 \mu \mathrm{g})$ and Tetracycline (TE30 $\mu \mathrm{g})$. All the antibiotic discs were procured from Oxoid Ltd, England.

\section{Determination of the minimum inhibitory concentrations (MIC) of cefepime}

The antimicrobial activity of cefepime, a fourth generation cephalosporin, was tested by determination of its MIC values against the 113 bacterial isolates and one standard E. coli ATCC 8739 strain by using the agar dilution technique (Andrews, 2001).

\section{Detection of ESBL Production}

Modified Double Disc Synergy test (MDDST):

All the isolates which showed a diameter of less than $25 \mathrm{~mm}$ for ceftriaxone in the antimicrobial susceptibility testing were selected for checking for ESBL production. This test was done by using a disc of amoxicillin-clavulanate $(20 / 10 \mu \mathrm{g})$ along with four cephalosporins; $3^{\text {rd }}$ generation, cefotaxime, ceftriaxone, ceftazidime and $4^{\text {th }}$ generation, cefepime. A lawn culture of the organisms was made on a Mueller-Hinton agar plate, an amoxicillin-clavulanate disc $(20 / 10 \mu \mathrm{g})$ was placed in the centre of the plate and the discs of $3^{\text {rd }}$ and $4^{\text {th }}$ generation cephalosporins were placed $15 \mathrm{~mm}$ and $20 \mathrm{~mm}$ apart respectively, centre to centre to that of the amoxicillin-clavulanate disc. Any distortion or increase in the zone towards the disc of amoxicillin-clavulanate was considered as positive for ESBL production (Kaur et al., 2013).

\section{Confirmatory Test for detection of ESBLs by Disk diffusion method}

A lawn culture of the organisms was streaked on a Mueller-Hinton agar plate. 
Then cefotaxime and ceftazidime discs, alone and in combination with clavulanic acid were placed on the surface of the agar plate. $\mathrm{A} \geq 5$-mm increase in a zone diameter for either antimicrobial agent tested in combination with clavulanic acid vs its zone when tested alone indicated positive ESBL production (Nadeem et al., 2009).

\section{Three-dimensional (3D) test}

Heavy suspensions of tested isolates were prepared and the cells were lysed by repeated freezing and thawing (10 times). A lawn culture of $E$. coli ATCC 8739 was made on Mueller Hinton agar plate and a disc of amoxicillin-clavulanate $(20 / 10 \mu \mathrm{g})$ was placed on the surface. Four narrow slits measuring $15 \mathrm{~mm}$ in length and $2-3 \mathrm{~mm}$ in width were cut out five millimeter from the edge of the disc.

The lysed suspension was centrifuged and $30 \mu 1$ of the supernatant were carefully delivered into the slits. The plates were incubated at $37^{\circ} \mathrm{C}$ without inverting them. Proteus isolates were tested on MacConkey's agar to prevent any possible swarming. Enhanced growth of E. coli ATCC 8739 at the point where the slits intersected the zone of inhibition was considered a positive three-dimensional test result and was interpreted as evidence for the presence of ESBLs(Coudron et al., 2000).

\section{AmpC Detection}

After an initial screening with cefoxitin (FOX $30 \mu \mathrm{g}$ ) discs, isolates which showed resistance to cefoxitin and susceptibility to cefepime were further tested for the AmpC enzyme production.

\section{AmpC disc test}

A lawn culture of a 0.5 McFarland's suspension of E. coli ATCC 8739 was prepared on a Mueller-Hinton agar plate. A $30 \mu \mathrm{g}$ cefoxitin disc was placed on the inoculated surface of the agar. A sterile plain disc $(6 \mathrm{~mm})$ was inoculated with several colonies of the test organism and placed beside the cefoxitin disc, almost touching it. After an overnight incubation at $37^{\circ} \mathrm{C}$, the plate was examined for either an indentation or a flattening of the zone of inhibition, which indicated the enzyme inactivation of cefoxitin (positive result), or an absence of distortion, which indicated no significant inactivation of cefoxitin (negative result).

\section{Three-dimensional (3D) test}

This test was performed as mentioned above but a cefoxitin disc $(30 \mu \mathrm{g})$ was placed on the surface of the Mueller Hinton agar. Enhanced growth of E. coli ATCC 8739 at the point where the slits intersected the zone of inhibition was considered a positive three-dimensional test result and indicated presence of AmpC $\beta$-lactamase.(Coudron et al., 2000)

\section{Clover leaf test (cefoxitin Hodge test)}

A Mueller-Hinton agar plate was swabbed with a culture of the $\beta$-lactamase nonproducing strain of E. coli ATCC 8739. A cefoxitin disc $(30 \mu \mathrm{g})$ was placed in the centre of the plate and four test strains were heavily streaked radially outward from the disc to produce growth about $0.25 \mathrm{~cm}$ wide. The plate was incubated at $37^{\circ} \mathrm{C}$ for $18-24$ hrs and then examined for the presence of clover leaf pattern. If the strains produced AmpC $\beta$-Lactamase, the zone produced by the ATCC strain was inhibited where the zones of growth of ATCC strain and test strains coincide thus giving rise to a clover leaf pattern. If the test strains did not produce $\beta$-lactamase no clover leaf pattern was produced.(Rand et al., 2011) 
Induction of cefepime resistance among selected cefepime sensitive isolates

Induction of cefepime resistance was done according to Page et al., with some modifications (Page et al., 2011). Selected isolates sensitive to cefepime were inoculated in $2 \mathrm{ml}$ nutrient broth containing $1 / 4 \mathrm{MIC}$ of cefepime at $37{ }^{\circ} \mathrm{C}$ for $24 \mathrm{hrs}$. One hundred $\mu$ l of the treated overnight system were subcultured in $2 \mathrm{ml}$ nutrient broth containing $1 / 4$ MIC of cefepime. This passage was then repeated consecutively for five days. The MIC was then determined by the agar dilution technique.

\section{Testing the stability of induced resistance to cefepime in the tested isolates}

Isolates with induced resistance to cefepime were subcultured in $2 \mathrm{ml}$ nutrient broth free of cefepime and incubated at $37{ }^{\circ} \mathrm{C}$ for 24 hrs. One hundred $\mu \mathrm{l}$ of this culture were then passed in $2 \mathrm{ml}$ of nutrient broth free of cefepime. This passage was repeated consecutively for five days. MIC of the subcultured isolates was determined after five passages to assure the stability of the acquired resistance of the isolates (Page et al., 2011).

\section{Results and Discussion}

After Identification of the 113 Gram negative clinical isolates, they were found to be 38 (33.6\%) E. coli, 25 (22.1\%) Pseudomonas spp, 23 (20.4\%) Klebsiella spp, 15 (13.3\%) Acinetobacter spp., 6 (5.3\%) Proteus spp, and 6 (5.3\%) Serratia spp. The prevalence of antibiotics resistance among the tested clinical isolates is shown in (Figure 1).

Multidrug resistance was observed among $60 \%$ of E. coli isolates, $75 \%$ of Klebsiella isolates, $70 \%$ of Pseudomonas isolates, 60\% of Acinetobacter isolates and $100 \%$ of
Proteus isolates and Serratia isolates. Although the use of cefepime in Egypt is relatively recent, however, the prevalence of cefepime resistance among the tested isolates was found to be $79 \%$ distributed as $53 \%$ of E. coli, $65 \%$ of Klebsiella spp., $44 \%$ of Pseudomonas spp., $73 \%$ of Acinetobacter spp., $33 \%$ of Proteus spp. and $83 \%$ of Serratia spp.. Our results showed lower resistance of Pseudomonas spp and Proteus spp. to cefepime. This confirms the antipseudomonal activity of cefepime which is in agreement with the study made by Kotwal et al. in India on 618 isolates of $P$. aeruginosa; they reported that cefepime was recommended as the drug of choice in patients in which $P$. aeruginosa was a predominant pathogen (Kotwal et al., 2014).

In this study, meropenem was found to be the most effective antibiotic against all the tested isolates where the resistance level was only $23 \%$ (Figure 1). Our results are similar, to some extent, to those reported by Jones et al. (Jones et al., 2002), Iroha et al.(Iroha et al., 2015), Cho et al.(Cho et al., 2015), Chen et al.(Chen et al., 2015) who found that carbapenems (biapenem, meropenem and imipenem) exhibited high antimicrobial activities against Gram-negative bacteria especially E. coli and Klebsiella pneumoniae. Also Turner examined the activity of meropenem against a total of 5208 isolates of Enterobacteriaceae; the susceptibility rate for meropenem was (99.4\%). It was mostly effective against the non-fermenters (Turner, 2009).

\section{Determination of MIC to cefepime}

The MIC values of cefepime ranged from 0.125 to more than $1024 \mu \mathrm{g} / \mathrm{ml}$ with an MIC50 of $32 \mu \mathrm{g} / \mathrm{ml}$ and an MIC90 of $1024 \mu \mathrm{g} / \mathrm{ml}$.

The results are shown in (Figure 2) where 24 isolates were cefepime sensitive and 89 
isolates were resistant according to the MIC breakpoints of cefepime that was mentioned by CLSI 2011 as follows: an MIC $\leq 8 \mu \mathrm{g} / \mathrm{ml}$ was considered to be sensitive while an MIC $\geq 32 \mu \mathrm{g} / \mathrm{ml}$ was resistant.

\section{ESBL detection}

Detection of ESBL producers among clinical isolates of Gram-negative bacilli (GNB) remains an important issue for infection control, especially in ICUs, where infections due to ESBL-producing bacteria are associated with dismal clinical outcome (Jean et al., 2015).

Various phenotypic methods are recommended in the routine practice to detect the ESBL production in GNB. One of which is the Double Disc Synergy Test (DDST) which uses the third generation cephalosporins (3GCs) is a simple and a reliable method. But the coexistence of AmpC may give false negative results as the AmpC type of $\beta$-lactamase inhibits the action of clavulanate. Hence, it obscures the synergistic effect of clavulanic acid and the 3GCs which are used. Therefore, this method was modified to improve the ESBL detection by using the fourth generation cephalosporin (cefepime) along with the third generation cephalosporins in DDST as this drug is stable to AmpC $\beta$-lactamase. Thus, it will demonstrate the synergy which arises from the inhibition of ESBL by clavulanate in the presence of the AmpC enzyme (Kaur et al., 2013).

After the antimicrobial susceptibility testing of all our isolates, we found that $98(87 \%)$ isolates showed inhibition zone diameters of less than $25 \mathrm{~mm}$ for ceftriaxone and/or $\leq 22$ $\mathrm{mm}$ for ceftazidime. These isolates were selected for checking the ESBL, so they were subjected to three phenotypic methods: MDDST, confirmatory disk diffusion method and 3D test. Forty seven isolates
(48\% of the tested isolates) gave positive results with the MDDST (Figure 3), the confirmatory disk diffusion test detected only $36(36.7 \%)$ isolates, and failed to detect ESBL in 11 isolates $(5 \mathrm{E}$. coli, 4 Klebsiella spp. and 2 Proteus spp). The 3D method (Figure 4) detected ESBL in about 54 (55\%) isolates. Results of ESBL detection are shown in Table 1.

The prevalence of ESBL production within our isolates was: $24(80 \%)$ out of $30 \mathrm{E}$. coli, $10(48 \%)$ out of 21 Klebseilla spp., 16 (67\%) out of 24 Pseudomonas spp., 7 (54\%) out of 13 Acinetobacter spp., 2 (50\%) out of 4 Serratia spp., 2 (33.3\%) out of 6 Proteus spp. In Latin America in 2012, Gales et al. investigated the frequency and resistance rates of GNB isolated from 10 Latin American medical centers located in Argentina, Brazil, Chile, and Mexico. Of a total $5704 \mathrm{GNB}$, they found that ESBL rates were $18.1 \%, 12.8 \%, 23.8 \%$, and $48.4 \%$ among $E$. coli and 60.4\%, 49.9\%, 59.2\%, and $33.3 \%$ among Klebsiella spp. from Argentina, Brazil, Chile and Mexico respectively (Gales et al., 2012). Another study done by Villegas et al. on 1,003 Gram-negative bacterial isolates. The most commonly isolated organism was $E$. coli, of which $26.8 \%$ were ESBL positive, while among the $K$. pneumoniae isolates, $37.7 \%$ were ESBL positive (Villegas et al., 2011). In 2009, Gharib et al. determined the existence of ESBL producing GNB by the DDST. They found that out of 176 isolated GNB, 106 (60.2\%) were confirmed as ESBL producers, mostly E. coli $(34 \%)$ followed by Klebsiella spp. (30.2\%) and Pseudomonas spp. (24.5\%) (Gharib et al., 2009).

All our isolates that were found to be positive ESBLs producers by the MDDST also showed positive results in disk diffusion method except for eleven isolates $(5 \mathrm{E}$. coli, 4 Klebsiella spp. and 2 Proteus spp.) which were positive for ESBL by MDDST but 
showed negative results with the disk diffusion method because they showed synergy with cefepime only in MDDST but not with any of the other third-generation cephalosporins which were used. Our results were similar, to some extent, to those reported by Kaur et al. as they found that of the 136 isolates, $112(82 \%)$ and 102(75\%) were positive for ESBL by the MDDST and the disk diffusion methods respectively. Ten (7.4\%) isolates (eight $E$. coli and two $K$. pneumoniae) were positive for ESBL by MDDST, yielded negative results with the disk diffusion disk method and therefore they reported that cefepime improves the sensitivity of MDDST in detecting ESBL producing bacteria (Kaur et al., 2013).

In order to compare and confirm results of MDDST for ESBL producers, Threedimensional (3D) test was carried out on the same isolates. It detected ESBL in 54 $(55.1 \%)$ isolates whereas $47(48 \%)$ isolates were detected by MDDST, and $7(7.14 \%)$ isolates were missed by MDDST. So, the three dimensional test has been found to be better than Double disc synergy test in the detection of ESBLs. (Figure 5)

Our results were exactly in accordance with Biswas et al. in Dhaka 2013 who reported that ESBL positivity was $80 \%$ by three dimensional method and $66.36 \%$ by MDDST method where $13.63 \%$ ESBL producing isolates were missed by Double disc synergy method (Biswas et al., 2014). Also in a study in India Menon et al. reported $85.7 \%$ ESBL positivity by three dimensional test and $14.2 \%$ positivity by double disc synergy test (Menon et al., 2006). Dhara et al. also demonstrated the superiority of MDDST over DDST for the ESBL detection (Dhara et al., 2012).

\section{AmpC detection}

AmpC $\beta$-lactamases are one of the important causes of drug resistance in Gram-negative bacteria. Both ESBLs and AmpC $\beta$ lactamases may be produced together by an organism but generally the effect of plasmid mediated AmpC $\beta$-lactamases masks the effect of ESBLs which may then be wrongly reported as ESBL negative. Failure to detect these enzymes has contributed to their uncontrolled spread and many times to therapeutic failures (Maraskolhe et al., 2014). While CLSI recommendations are available for detection of ESBLs producing isolates of E. coli and Klebsiella spp., there are no such guidelines for detection of AmpC $\quad \beta$-lactamases (Wayne, 2011). Therefore our study tended to detect AmpC $\beta$-lactamases produced by Gram-negative bacteria using three phenotypic laboratory tests: AmpC disc test, cloverleaf test and Three-dimensional (3D) test.

After screening the clinical isolates for susceptibility to cefepime (FEP) and cefoxitin (FOX); there were 37 isolates sensitive for cefepime and showed resistance to cefoxitin; this was an initial indicator for being AmpC producers. The isolates were: 13 Pseudomonas spp., $12 \mathrm{E}$. coli, 6 Klebsiella spp., 3 Proteus spp., 2 Acinetobacter spp. and 1 Serratia spp. These isolates were further tested by AmpC disc test, Clover leaf method and 3D method. Our results showed that the $3 \mathrm{D}$ test (Figure 5 ) is the most sensitive test for AmpC detection followed by AmpC disc test (48.6\% and $29.7 \%$ respectively), and that the clover leaf method (Figure 6) was the least sensitive method (13.5\%). Results are shown in Table 2.

Also Rand et al. agreed that the modified Hodge test when compared with other methods of detecting AmpC expression such as the boronic acid test and the EDTA disk test, it was found to be less sensitive (Rand et al., 2011). In another study carried out by Vinoth et al. the Hodge test declared 60 /90 
of the isolates to be positive and Amp C disk test showed 56 to be positive (Vinoth et al., 2012). In our study, 11 isolates were co- producers (produce both ESBLs and AmpC); they were 5 E. coli, 4 Klebsiella spp. and 2 Proteus spp.

Table.1 Results of MDDST, Confirmatory disk diffusion method and 3D methods for ESBLs detection

\begin{tabular}{|c|c|c|c|c|c|c|c||}
\hline \multirow{2}{*}{$\begin{array}{c}\text { Method } \\
\text { Isolates }\end{array}$} & \multicolumn{2}{|c|}{ MDDST } & $\begin{array}{c}\text { CLSI Confirmatory } \\
\text { disk diffusion } \\
\text { method }\end{array}$ & \multicolumn{2}{|c|}{ 3D } & $\begin{array}{c}\text { Total } \\
\text { number } \\
\text { of } \\
\text { isolates }\end{array}$ \\
\cline { 2 - 8 } & Positive & Negative & Positive & Negative & Positive & Negative \\
\hline \hline $\begin{array}{c}\text { Escherichia } \\
\text { coli }\end{array}$ & 24 & 6 & 19 & 11 & 17 & 13 & 30 \\
\hline $\begin{array}{c}\text { Pseudomonas } \\
\text { spp. }\end{array}$ & 6 & 18 & 6 & 18 & 16 & 8 & 24 \\
\hline $\begin{array}{c}\text { Klebsiella } \\
\text { spp. }\end{array}$ & 9 & 12 & 5 & 16 & 10 & 11 & 21 \\
\hline $\begin{array}{c}\text { Acinetobacter } \\
\text { spp. }\end{array}$ & 5 & 8 & 5 & 8 & 7 & 6 & 13 \\
\hline \begin{tabular}{c} 
Proteus spp. \\
\hline Serratia spp.
\end{tabular} & 1 & 3 & 0 & 6 & 2 & 4 & 6 \\
\hline Total & 47 & $51(52 \%)$ & $\begin{array}{c}36 \\
(47 \%)\end{array}$ & $\begin{array}{c}62 \\
(63 \%)\end{array}$ & $\begin{array}{c}54 \\
(55 \%)\end{array}$ & $\begin{array}{c}(45 \%) \\
(100 \%)\end{array}$ \\
\hline
\end{tabular}

Table.2 Results of AmpC disc test, clover leaf method and 3D methods for AmpC detection

\begin{tabular}{|c|c|c|c|c|c|c|c||}
\hline \multirow{2}{*}{ Methods } & \multicolumn{2}{|c|}{ AmpC disc test } & \multicolumn{2}{|c|}{ clover leaf method } & \multicolumn{2}{|c|}{ 3 D method } & \multirow{2}{*}{ Total } \\
\cline { 2 - 8 } & Positive & Negative & Positive & Negative & Positive & Negative & \\
\hline \hline E. coli & 4 & 8 & 2 & 10 & 6 & 6 & 12 \\
\hline Pseudomonas spp & 3 & 10 & 1 & 12 & 2 & 11 & 13 \\
\hline Klebsiella spp & 3 & 3 & 2 & 4 & 5 & 1 & 6 \\
\hline Acinetobacter spp. & 0 & 2 & 0 & 2 & 2 & 0 & 2 \\
\hline Serratia spp. & 0 & 1 & 0 & 1 & 1 & 0 & 1 \\
\hline Proteus spp. & 1 & 2 & 0 & 3 & 2 & 1 & 3 \\
\hline Total & 11 & $\begin{array}{c}26 \\
(70.3 \%)\end{array}$ & $\begin{array}{c}5 \\
(13.5 \%)\end{array}$ & $\begin{array}{c}32 \\
(86.5 \%)\end{array}$ & $\begin{array}{c}18 \\
(48.6 \%)\end{array}$ & $\begin{array}{c}19 \\
(51.4 \%)\end{array}$ & $\begin{array}{c}37 \\
(100 \%)\end{array}$ \\
\hline
\end{tabular}


Table.3 Induction of cefepime resistance among selected sensitive isolates.

\begin{tabular}{|c|c|c|c|}
\hline \multirow{2}{*}{$\begin{array}{c}\text { Selected } \\
\text { isolates }\end{array}$} & \multicolumn{3}{|c|}{ Cefepime MIC $(\mu \mathrm{g} / \mathrm{ml})$} \\
\hline & Initial MIC & $\begin{array}{l}\text { After induction by } 1 / 4 \\
\text { MIC }\end{array}$ & $\begin{array}{l}\text { stability of the } \\
\text { induced resistance }\end{array}$ \\
\hline PS1 & 4 & 16 & 8 \\
\hline E2 & 8 & 64 & 32 \\
\hline PS7 & 2 & 4 & 4 \\
\hline PS92 & 8 & 16 & 8 \\
\hline PS97 & 4 & 16 & 16 \\
\hline E104 & 16 & 32 & 32 \\
\hline $\mathrm{AC} 114$ & 16 & 128 & 64 \\
\hline AC144 & 1 & 16 & 16 \\
\hline $\mathrm{AC} 77 \mathrm{~b}$ & 8 & 16 & 16 \\
\hline AC110 & 16 & 32 & 32 \\
\hline E125 & 0.125 & 8 & 4 \\
\hline E43 & 0.125 & 32 & 16 \\
\hline AC78 & 8 & 128 & 64 \\
\hline E124 & 0.25 & 64 & 32 \\
\hline
\end{tabular}

Fig.1 Prevalence of antibiotic resistance among the tested clinical isolates.

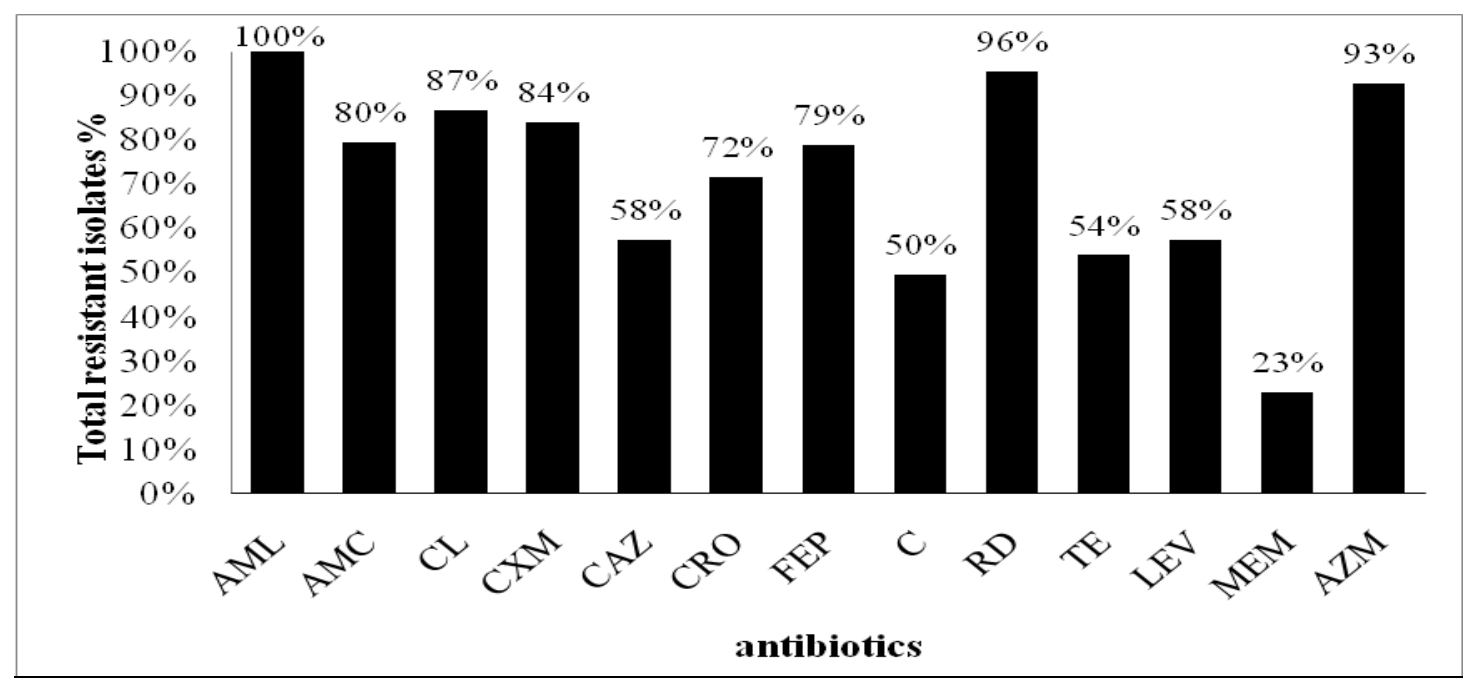


Fig.2 Pattern of MICs of Cefepime against the tested isolates

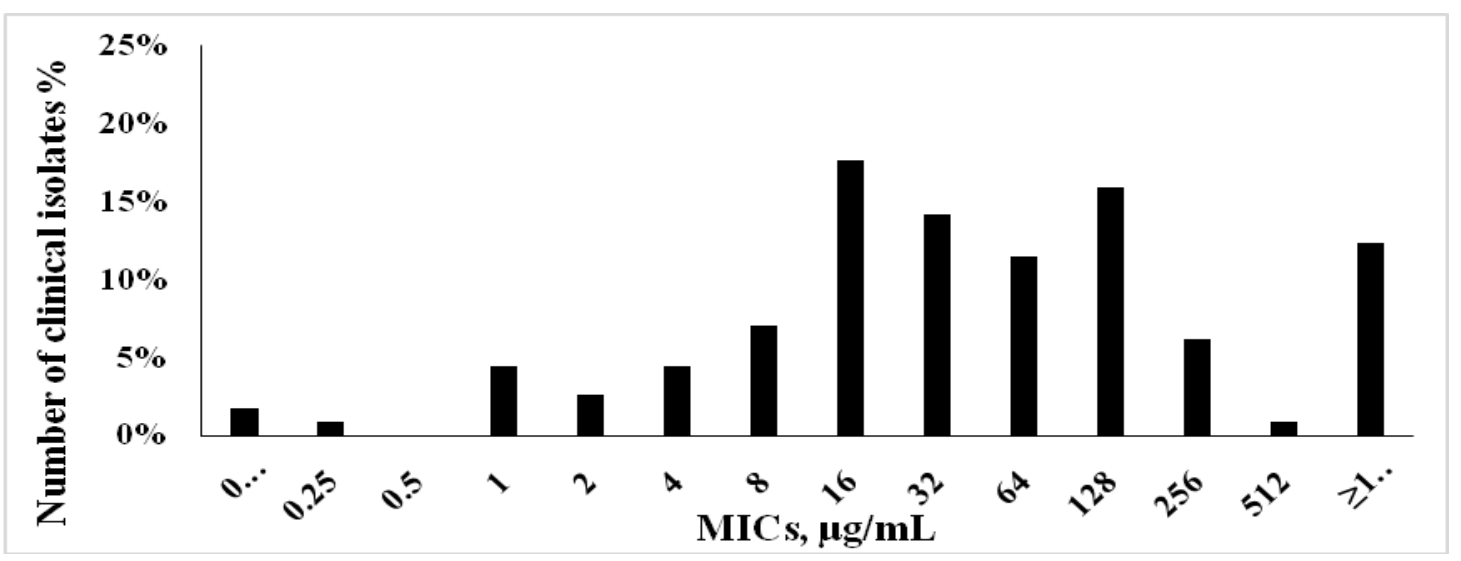

Fig.3 Positive MDDST distortion or increase in the zone towards the disc of amoxicillinclavulanate indicating ESBL production.

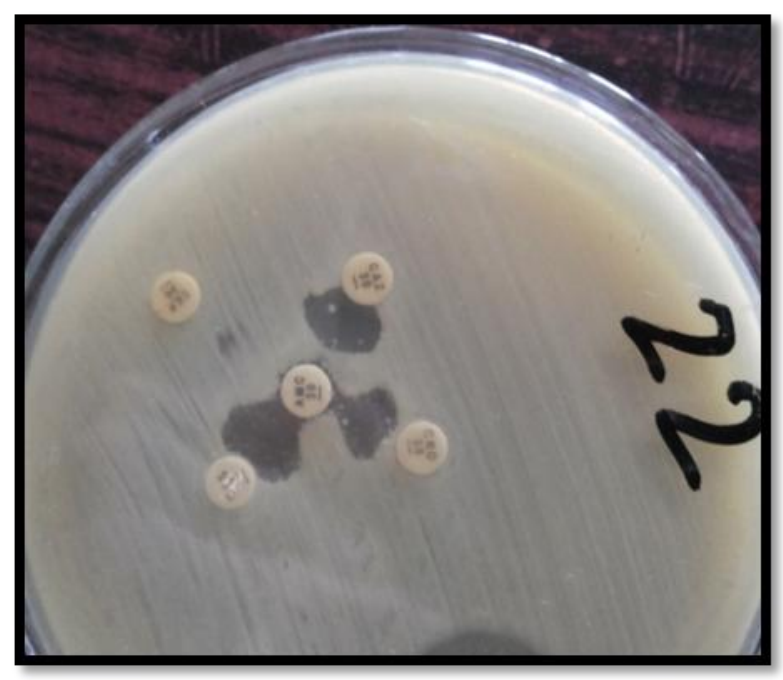

Fig.4 Positive 3D test showing enhanced growth of E. coli ATCC 8739 at the point where the slits intersected the zone of inhibition

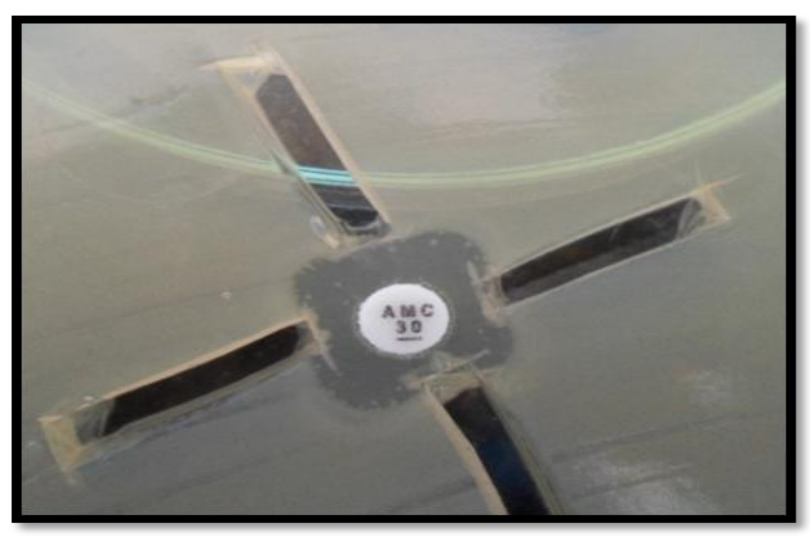


Fig.5 Positive 3D test for AmpC detection where enhanced growth of E. coli ATCC 8739 at the point where the slits intersected the zone of inhibition was observed.

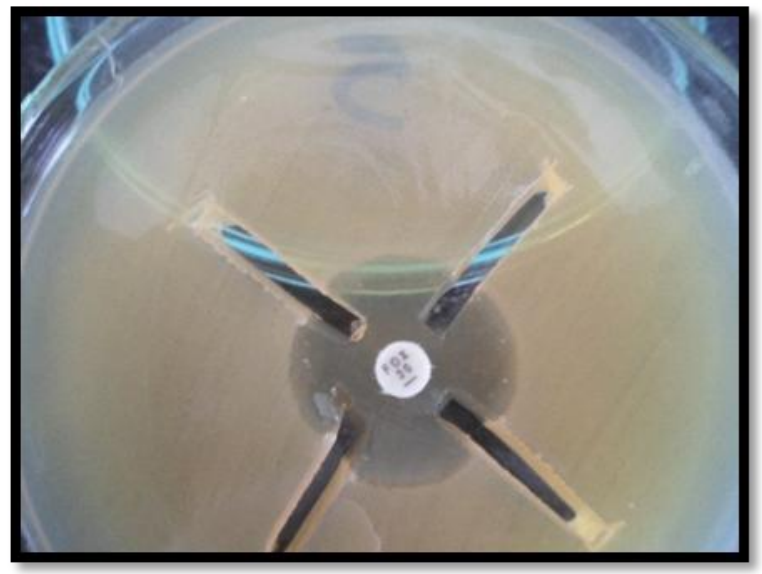

Fig.6 Positive clover leaf test where the inhibition zone produced by the E. Coli ATCC 8739 strain was inhibited due to the growth of the test strains thus giving rise to a clover leaf pattern.

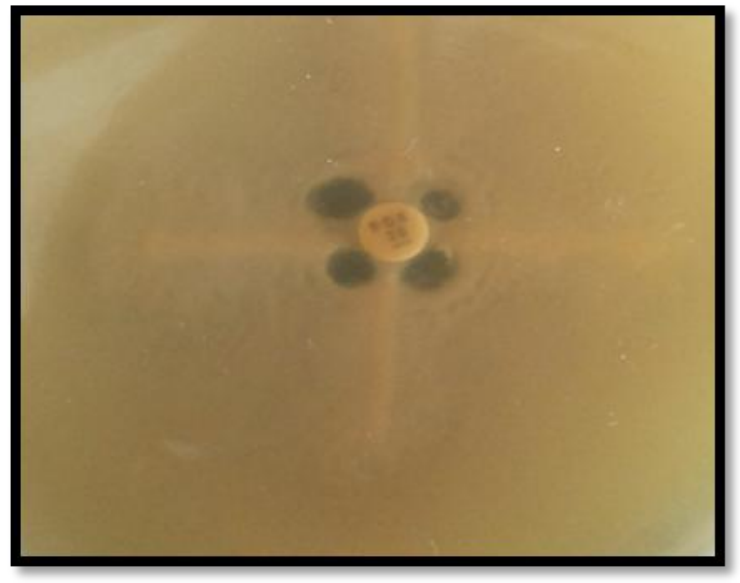

Fig.7 Induction of resistance in the selected isolates by using 1/4 MIC of cefepime.

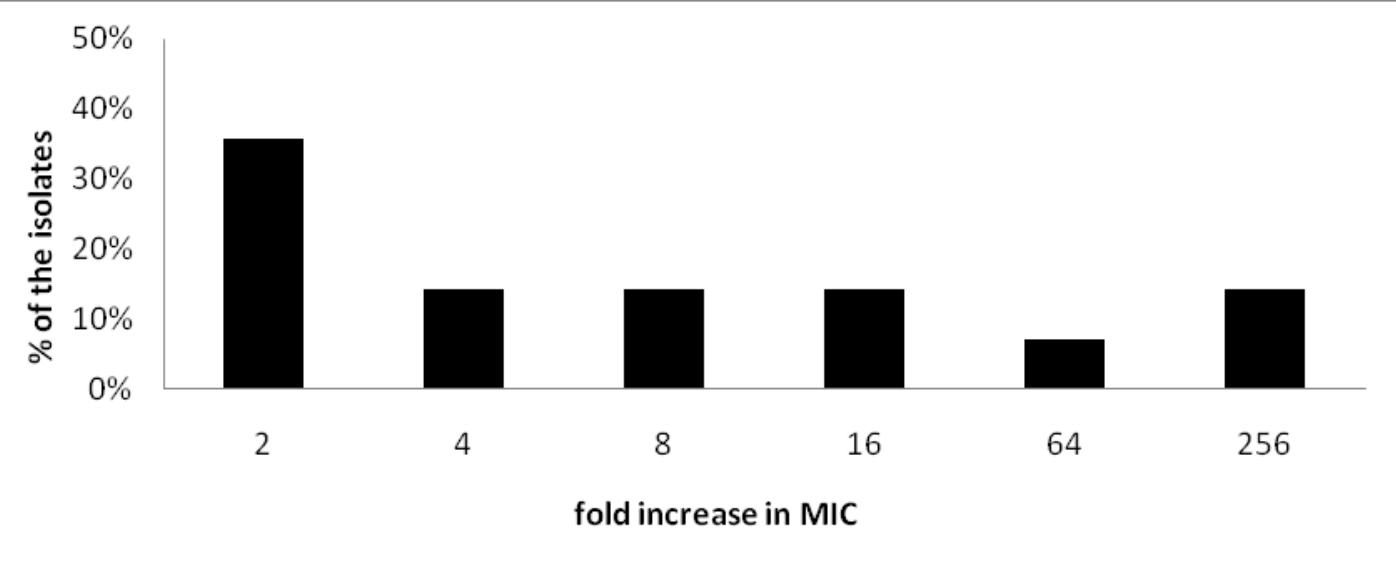




\section{Induction of resistance against cefepime}

After induction of cefepime resistance, the MIC increased by 2, 4, 8, 16, 64 and 256 folds in $35.7 \%, 14.3 \%, 14.3 \%, 14.3 \%, 7.1 \%$ and $14.3 \%$ of the tested isolates respectively (Table 3, Figure 7). This can be explained by stimulating the production of $\beta$ lactamases since five isolates of these induced resistant isolates were investigated again for ESBL production by using cefepime alone and cefepime/clavulanic acid discs and they showed positive results where the difference in inhibition zone diameter between cefepime/clavulanic acid and cefepime alone discs was $>5 \mathrm{~mm}$.

All the selected isolates showed stability of the induced resistance where the MIC values of cefepime against them were the same or lower by one fold than the MIC values after induction. (Table 3) However, Gradelski et al. investigated the step-wise resistance to cefepime for $16 P$. aeruginosa strains by daily transfer for 7 days to fresh media containing two-fold serial dilution of antibiotic. By the third transfer no strains became resistant to cefepime but at the end of the 7 day serial transfer, four $(25 \%)$ of the 16 strains were resistant to cefepime (Gradelski et al., 1993).

Another study in 2011 was carried out by Page et al. who studied the development of resistance to cefepime by serial passage over increasing concentrations of cefepime in microtiter plates using initial inoculum $10^{6} \mathrm{CFU} / \mathrm{ml}$. They found that Strains with >4-fold elevated MICs toward cefepime appeared within 4 passages suggesting that they had higher levels of expression of $\beta$ lactamase (Page et al., 2011).

In conclusion, nosocomial Gram-negative pathogens such as E. coli, Klebsiella spp., Pseudomonas spp. and Acinetobacter spp. are becoming increasingly resistant to commonly used antimicrobial agents and the extensive use of broad-spectrum antibiotics produces multidrug resistant strains. Carbapenems remain the drugs of choice for extended spectrum $\beta$-lactamase (ESBLs) producing Gram negative bacteria. Until proven otherwise, confirmed ESBLproducing isolates should be reported as resistant to all penicillins and cephalosporins to avoid therapy with antibiotics that may be clinically ineffective. Confirmatory test for ESBLs detection based on ceftazidime and cefotaxime tested alone and in combination with clavulanate is useful but has limitation in that it can yield false negative results with isolates that produce a high level of AmpC so the application of the double disc synergy tests that combine amoxicillin-clavulanate with cefepime, may increase the possibility of the ESBLs detection. Cefepime should not be used alone for prolonged periods because it induces self-resistance by stimulating bacteria to produce $\beta$ lactamases.

\section{References}

Andrews, J., Testing, B.W.P.o.S. 2006. BSAC standardized disc susceptibility testing method (version 5). $J$. Antimicrob. Chemother., 58:511-529.

Andrews, J.M. 2001. Determination of minimum inhibitory concentrations. $J$. Antimicrob. Chemother., 8: 5-16.

Biswas, S., Mia, M., Ara, N., Ibrahim, M., Nasir, T., Yunus, S. 2014. Comparison of Three Dimensional Test and Double Disc Synergy Test for detection of Extended Spectrum $\beta$-Lactamase (ESBL) producing Gram negative bacteria. Pulse, 6:12-19.

Bradford, P.A. 2001. Extended-spectrum $\beta$ lactamases in the 21st century: characterization, epidemiology, and detection of this important resistance 
threat. Clin. Microbiol. Rev., 14:933951.

Chen, H., Wang, Z., Li, H., Wang, Q., Zhao, C., He, W., Wang, X., Zhang, F., Wang, H. 2015. In vitro activities of 16 antimicrobial agents against Gramnegative bacteria from six teaching hospitals in China. Jpn. J. Infect. Dis., 4:263-267.

Cho, Y.H., Jung, S.I., Chung, H.S., Yu, H.S., Hwang, E.C., Kim, S.-O., Kang, T.W., Kwon, D.D., Park, K. 2015. Antimicrobial susceptibilities of extended-spectrum beta-lactamaseproducing Escherichia coli and Klebsiella pneumoniae in health careassociated urinary tract infection: focus on susceptibility to fosfomycin. Int. Urol. Nephrol., 47:1059-1066.

Coudron, P.E., Moland, E.S., Thomson, K.S. 2000. Occurrence and detection of AmpC beta-lactamases among Escherichia coli, Klebsiella pneumoniae, and Proteus mirabilis isolates at a veterans medical center. $J$. Clin. Microbiol., 38:1791-1796.

Dhara, M., Disha, P., Sachin, P., Manisha, J., Seema, B., Vegad, M. 2012. Comparison of various methods for the detection of extended spectrum beta-lactamase in Klebsiella pneumoniae isolated from neonatal intensive care unit. Ahmedabad. NJMR, 2: 348-355.

Gales, A.C., Castanheira, M., Jones, R.N., Sader, H.S. 2012. Antimicrobial resistance among gram-negative bacilli isolated from Latin America: results from SENTRY Antimicrobial Surveillance Program (Latin America, 2008-2010). Diagn. Microbiol. Infect. Dis., 73: 354-360.

Gharib, M.A., Ouda, N.H., Saeed, M., Hamed, L., Rahman, S.A. 2009. Prevalence of extended spectrum beta lactamase producers in an Egyptian
Critical Care Center. Egyptian J. Med. Microbiol., 18: 139-145.

Gradelski, E., Fung-Tomc, J., Huczko, E., Kessler, R.E. 1993. Development of resistance in Pseudomonas aeruginosa to broad-spectrum cephalosporins via step-wise mutations. J. Antimicrob. Chemother., 32:75-80.

Heffernan, H., Pope, C., Carter, P. 2007. Identification of extended-spectrum $\beta$ lactamase types, plasmid mediated AmpC $\beta$-lactamases and strains among urinary Escherichia coli and Klebsiella in New Zealand in 2006. Institute of Environmental Science and Research Limited.

Iroha, I., Afiukwa, F., Oji, A., Ejikeugwu, P., Nwakeze, E. 2015. Occurrence of extended spectrum beta lactamase producing escherichia coli from human clinical and wild birds (pigeons, bats, parrots and ducks) samples from Ebonyi State, Nigeria. World J. Pharm. Pharm. Sci., 4(7): 2029.

Jean, S.S., Lee, W.S., Bai, K.J., Lam, C., Hsu, C.W., Yu, K.W., Liao, C.H., Chang, F.Y., Ko, W.C., Wu, J.J. 2015. Relationship between the distribution of cefepime minimum inhibitory concentrations and detection of extended-spectrum $\quad \beta$-lactamase production among clinically important Enterobacteriaceae isolates obtained from patients in intensive care units in Taiwan: results from the Surveillance of Multicenter Antimicrobial Resistance in Taiwan (SMART) in 2007. J. Microbiol., Immunol. Infect., 48: 85-91.

Jones, R.N., Rhomberg, P.R., Varnam, D.J., Mathai, D. 2002. A comparison of the antimicrobial activity of meropenem and selected broad-spectrum antimicrobials tested against multidrug resistant Gram-negative bacilli 
including bacteraemic Salmonella spp.:: Initial studies for the MYSTIC programme in India. Int. $J$. Antimicrob. Agents, 20: 426-431.

Kaur, J., Chopra, S., Sheevani, G.M. 2013. Modified Double Disc Synergy Test to Detect ESBL Production in Urinary Isolates of Escherichia coli and Klebsiella pneumoniae. J. Clin. Diagn. Res., 7(2): 229-233.

Kotwal, A., Biswas, D., Kakati, B., Thakuria, B., Bhardwaj, N. 2014. Efficacy of anti-pseudomonal antibiotics: need to reconsider the empirical use of cefepime. The Indian J. Med. Res., 40: 560.

Maraskolhe, D., Deotale, V., Mendiratta, D., Narang, P. 2014. Comparision of Three Laboratory Tests for Detection of AmpC $\beta$ Lactamases in Klebsiella Species and E. Coli. J. Clin. Diagn. Res., 8: DC05-DC08.

Menon, T., Bindu, D., Kumar, C., Nalini, S., Thirunarayan, M. 2006. Comparison of double disc and three dimensional methods to screen for ESBL producers in a tertiary care hospital. Indian J. Med. Microbiol., 24:117.

Nadeem, S., Qasmi, S., Afaque, F., Saleem, M., Nadeem, S.H.S., Hakim, S. 2009. Comparison of the in vitro susceptibility of Clinical isolates of Pseudomonas aeruginos aeruginosa in a local hospital setting in Karachi, Pakistan a in a local hospital setting in Karachi, Pakistan a in a local hospital setting in Karachi, Pakistan. Br. J. Med. Pract., 2(4): 35-39.

Naumovski, L., Quinn, J., Miyashiro, D., Patel, M., Bush, K., Singer, S., Graves, D., Palzkill, T., Arvin, A. 1992. Outbreak of ceftazidime resistance due to a novel extendedspectrum beta-lactamase in isolates from cancer patients. Antimicrob. Agents Chemother., 36: 1991-1996.
O Gutkind, G., Di Conza, J., Power, P., Radice, M. 2013. $\beta$-lactamasemediated resistance: A biochemical, epidemiological and genetic overview. Curr. Pharm. Des., 19:164-208.

Page, M.G., Dantier, C., Desarbre, E., Gaucher, B., Gebhardt, K., SchmittHoffmann, A. 2011. In-vitro and Invivo Properties of BAL30376, a $\beta$ Lactam/Dual $\beta$-Lactamase Inhibitor Combination with Enhanced Activity against Gram-negative Bacilli that Express Multiple $\beta$-Lactamases. Antimicrob. Agents Chemother., 55(4): 1510-1519.

Paterson, D.L. 2006. Resistance in gramnegative bacteria: Enterobacteriaceae. The American J. Med., 19: S20-S28.

Rand, K.H., Turner, B., Seifert, H., Hansen, C., Johnson, J.A., Zimmer, A. 2011. Clinical Laboratory Detection of AmpC $\beta$-Lactamase. Am. J. Clin. Pathol. 135:572-576.

Sykes, R., Matthew, M. 1976. The $\beta$ lactamases of gram-negative bacteria and their role in resistance to $\beta$-lactam antibiotics. J. Antimicrob. Chemother., 2:115-157.

Tamma, P.D., Girdwood, S.C., Gopaul, R., Tekle, T., Roberts, A.A., Harris, A.D., Cosgrove, S.E., Carroll, K.C. 2013. The Use of Cefepime for Treating AmpC $\quad \beta$-Lactamase-Producing Enterobacteriaceae. Clin. Infect. Dis. 57:781-788.

Thomson, K.S., Sanders, C.C. 1992. Detection of extended-spectrum betalactamases in members of the family Enterobacteriaceae: comparison of the double-disk and three-dimensional tests. Antimicrob. Agents Chemother. 36:1877-1882.

Turner, P.J. 2009. MYSTIC Europe 2007: activity of meropenem and other broad-spectrum agents against 
nosocomial isolates. Diagn. Microbiol.

Infect. Dis. 63:217-222.

Villegas, M.V., Blanco, M.G., Sifuentes-

Osornio, J., Rossi, F. 2011. Increasing prevalence of extended-spectrumbetalactamase among Gram-negative bacilli in Latin America: 2008 update from the Study for Monitoring Antimicrobial Resistance Trends (SMART). Braz. J. Infect. Dis. 15:3439.

Vinoth, J., Begum, E.S., Kumar, R.S., Ramesh, S. 2012. Phenotypic detection and antibiogram of Amp C Beta Lactamases Producing Tribe
Proteeae In a Tertiary Care Hospital. Asian J. Pharm. Clin. Res. 5: 180-182.

Wayne, C. PA: Clinical Laboratory Standards Institute; 2011. Performance standards for antimicrobial susceptibility testing.

Yagi, T., Wachino, J.I., Kurokawa, H., Suzuki, S., Yamane, K., Doi, Y., Shibata, N., Kato, H., Shibayama, K., Arakawa, Y. 2005. Practical methods using boronic acid compounds for identification of class $\mathrm{C} \beta$-lactamaseproducing Klebsiella pneumoniae and Escherichia coli. J. Clin. Microbiol., 43: 2551-2558.

\section{How to cite this article:}

Moustafa A. El-Nakeeb, Hoda M. Omar, Rania Abozahra and Eman Badr. 2016. Comparative Study of Different Methods of Detection of $\beta$-lactamase Production in Gram Negative Bacterial Isolates and Studying Induction of Resistance to Cefipime. Int.J.Curr.Microbiol.App.Sci. 5(11): 106-120. doi: http://dx.doi.org/10.20546/ijcmas.2016.511.012 